\title{
Isobaric peptide labeling on digital microfluidics for quantitative low cell number proteomics
}

Jan Leipert ${ }^{1}$, Max K. Steinbach ${ }^{1}$, and Andreas Tholey ${ }^{1, *}$

${ }^{1}$ Systematic Proteome Research \& Bioanalytics, Institute for Experimental Medicine, ChristianAlbrechts-Universität zu Kiel, Kiel, Germany

*to whom correspondence should be addressed:

Andreas Tholey

Systematic Proteome Research \& Bioanalytics, Institute for Experimental Medicine

Christian-Albrechts-Universität zu Kiel

24105 Kiel, Germany

Phone: \#49 (431) 500 30300; Fax: \#49 (431) 50030308

E-mail: a.tholey@iem.uni-kiel.de 


\section{Table of contents}

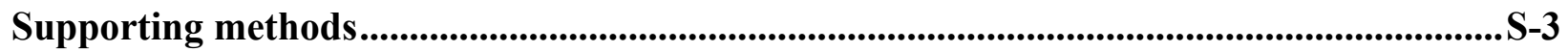

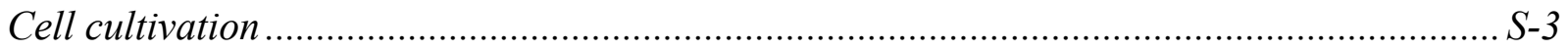

Doxorubincin treatment of Jurkat T cells ........................................................................... S-3

LC MALDI-TOF MS analysis of detergent retention times .............................................. S-4

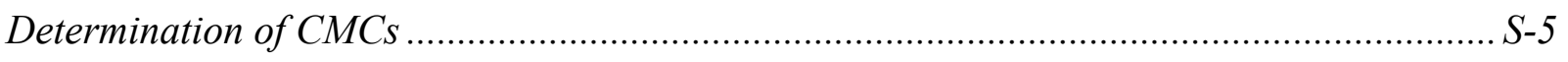

Analysis of LC-MS Data............................................................................................... S-5

Supporting figures ............................................................................................................................ S-7

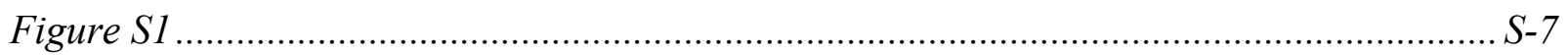

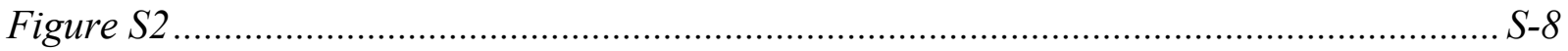

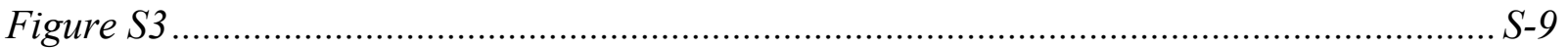

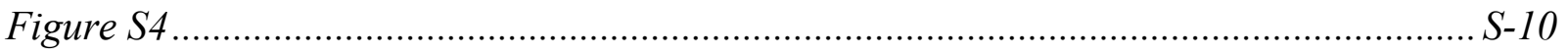

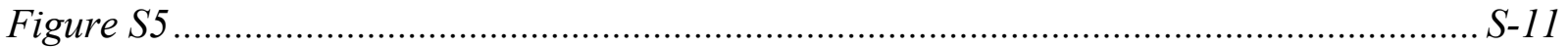

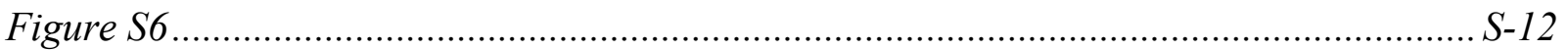

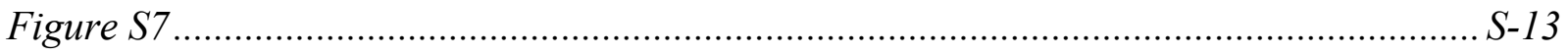

Figure S8

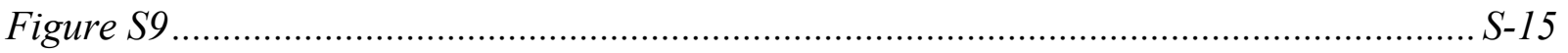

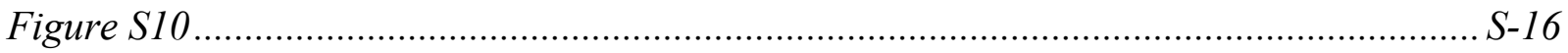

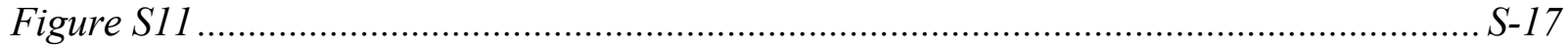

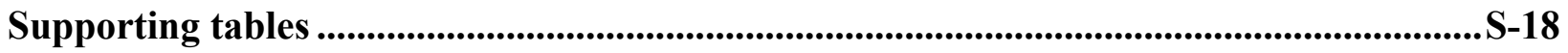

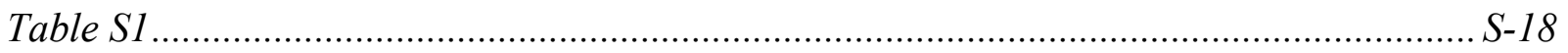

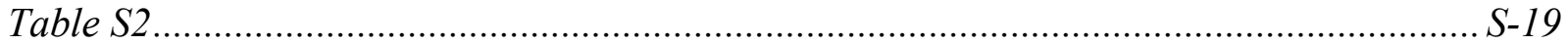

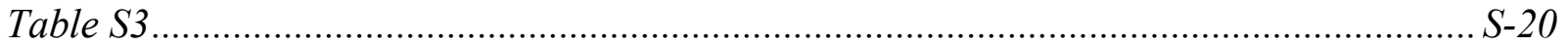

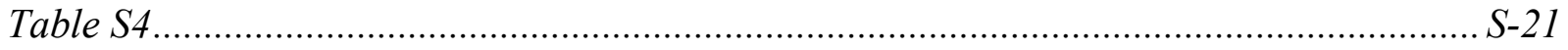

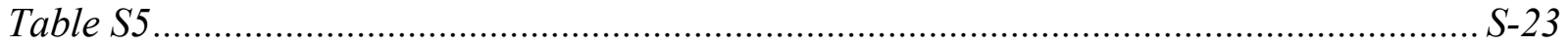

Supporting references.............................................................................................................................. S-25 


\section{Supporting methods}

\section{Cell cultivation}

A Jurkat T cell line (clone E6.1) (CLS Cell Lines Service GmbH, Eppelheim, Germany) was cultivated in RPMI 1640 medium containing 25 mM HEPES, $2 \mathrm{mM}$ L-glutamine, and $0.013 \mathrm{mM}$ phenol red (CAT\# 52400017, Thermo Fisher Scientific, Bremen, Germany) supplemented with 10\% (v/v) fetal bovine serum (CAT\# A3160801, Thermo Fisher Scientific), and 1\% (v/v) of penicillin $(10.000 \mathrm{U} / \mathrm{mL})$ /streptomycin $(10.000 \mu \mathrm{g} / \mathrm{mL})(\mathrm{CAT} \#$ P4333, Sigma-Aldrich, Steinheim, Germany) in a $5 \% \mathrm{CO}_{2}$ atmosphere at $37^{\circ} \mathrm{C}$. Cell viability was assessed by staining with a $0.4 \%$ Trypan blue solution (Sigma-Aldrich). Suspensions of Jurkat T cells were harvested $\left(5 \times 10^{5}\right.$ cells $/ \mathrm{mL}$ ), centrifuged at $200 \mathrm{xg}$ and $4^{\circ} \mathrm{C}$, washed three times with cold PBS buffer, and pellets were subsequently used in experiments or stored at $-80^{\circ} \mathrm{C}$.

\section{Doxorubincin treatment of Jurkat T cells}

Treatment of Jurkat T cells with doxorubicin was performed as described previously. ${ }^{1}$ To a $5 \mathrm{~mL}$ culture of Jurkat T cells $\left(5 \times 10^{5}\right.$ cells $\left./ \mathrm{mL}\right)$, doxorubicin (CAT\# 5040420001, Sigma-Aldrich) diluted in medium was added to reach a final concentration of $1 \mu \mathrm{M}$. For untreated cells, the same volume of medium without doxorubicin was added. Cells were incubated for $24 \mathrm{hrs}\left(5 \% \mathrm{CO}_{2}\right.$, $37^{\circ} \mathrm{C}$ ), subsequently centrifuged at $200 \mathrm{x} \mathrm{g}$ and $4^{\circ} \mathrm{C}$ for $5 \mathrm{~min}$, and washed $3 \mathrm{x}$ with cold PBS buffer. Cell suspension were diluted to concentrations of 75 cells $/ \mu \mathrm{L}$ in cell sample buffer $(1 \mathrm{x}$ PBS, $0.1 \%$ Pluronic F68 (wt/vol)) by counting in a hemocytometer. 


\section{LC MALDI-TOF MS analysis of detergent retention times}

Detergents were spiked into a tryptic digest of Jurkat T cells diluted to 100 cell equivalents. LC was performed on a Dionex UltiMate 3000 HPLC equipped with a nanoflow splitting cartridge. Samples $\left(1 \mu \mathrm{L}\right.$ injections) were loaded onto an Acclaim PepMap $\mathrm{C}_{18}$ trap cartridge $(5 \mu \mathrm{m}, 0.3 \mathrm{~mm}$ x $5 \mathrm{~mm}, 100 \AA)$ and washed with loading eluent $(0.1 \% \mathrm{TFA} / 3 \% \mathrm{ACN}$ in water) at $30 \mu \mathrm{L} / \mathrm{min}$ for 5 min. Separation on an Acclaim PepMap $C_{18}$ analytical column $(75 \mu \mathrm{m} \times 250 \mathrm{~mm}, 3 \mu \mathrm{m}, 100 \AA \AA)$ was carried out at $300 \mathrm{~nL} / \mathrm{min}$ by a $90 \mathrm{~min}$ linear gradient ( $5 \%$ to $50 \% \mathrm{~B})$, followed by a $5 \mathrm{~min}$ step to $95 \%$ B, and a 10 min washing step (95\% B). After a 15 min column equilibration (5\% B), a second washing step (15 min, 99\% B) was performed, followed by equilibration (5\% B, $15 \mathrm{~min})$. Eluents used were $0.05 \%$ TFA in water (eluent A), and $0.04 \%$ TFA in $80 \%$ ACN / 20\% water (eluent B).

After UV detection at $214 \mathrm{~nm}$, eluent was mixed online with CHCA matrix $(3 \mathrm{mg} / \mathrm{mL}$ in $70 \%$ ACN, $0.1 \%$ TFA) delivered at $0.889 \mu \mathrm{L} / \mathrm{min}$ by the syringe of a ProBot microfraction collector (Dionex, Idstein, Germany). Eluates between min 90 to 135 were spotted onto an Opti-TOF LCMALDI target with 15 second spot intervals. LC-MALDI MS analysis was conducted on an AB SCIEX MALDI TOF/TOF 5800 mass spectrometer (SCIEX, Darmstadt, Germany) equipped with a Nd:YAG laser operating at a pulse rate of $400 \mathrm{~Hz}$. The instrument was calibrated in reflector positive ion mode in the mass range between $\mathrm{m} / \mathrm{z} 100$ and $\mathrm{m} / \mathrm{z} 600$ using CHCA matrix cluster signals.

Signal-to-noise $(\mathrm{S} / \mathrm{N})$ values of detergent $\mathrm{m} / \mathrm{z}$ values were extracted using the built-in Analysis Tool function of the TOF/TOF Series Explorer Software. Extracted ion chromatograms were generated by plotting peak $\mathrm{S} / \mathrm{N}$ against the LC-retention time corresponding to the respective spot. 


\section{Determination of CMCs}

CMCs were determined by the 1:3 pyrene ratio method described previously. ${ }^{2,3}$ Pyrene was dissolved by sonication (30 min) in $\mathrm{EtOH}$, and diluted to a concentration of $3 \mu \mathrm{M}$ in $0.25 \% \mathrm{EtOH}$ (v/v), or the same diluent containing 5\% ACN (v/v). Pyrene solution with or without ACN was subsequently used to dissolve and dilute detergents. Of each detergent concentration, $200 \mu \mathrm{L}$ were pipetted into black flat-bottom 96-well plates (Greiner Bio-One, Frickenhausen, Germany) in triplicates. Fluorescence intensities were measured on an Infinite M200Pro monochromator plate reader (Tecan, Crailsheim, Germany); excitation: $335 \mathrm{~nm}$, emission intensities of the $\mathrm{I}_{1}(372 \mathrm{~nm})$ and $\mathrm{I}_{3}(384 \mathrm{~nm})$ vibrational bands were recorded. To calculate the CMC, a Boltzmann-type sigmoid was fitted; ${ }^{3}$ outliers were removed as described previously. ${ }^{4}$

\section{Analysis of LC-MS Data}

Data files were processed using Proteome Discoverer (version 2.2.0.388) and searched using the SequestHT algorithm node against a human protein database (accessed from UniProt on the 2017/04/07) and the cRAP list of common laboratory contaminants. For UPS1-containing samples, a FASTA file supplied by the manufacturer was included. The Percolator node was used for false discovery rate (FDR) calculation and a target protein target FDR of 0.01 was employed. Search parameters were Enzyme: Trypsin (full), precursor mass tolerance: $10 \mathrm{ppm}$, fragment mass tolerance: 0.02 Da, Fixed modification: carbamidomethyl (C), Dynamic modification: oxidation (M). Modifications for TMT-labeled samples: Fixed: TMT (K, N-term), carbamidomethyl (C); Dynamic: oxidation (M). For analysis of underlabeling: Fixed: carbamidomethyl (C); Dynamic: 
TMT (K, N-term), oxidation (M). For analysis of overlabeling: Fixed: TMT (K, N-term), carbamidomethyl (C); Dynamic: TMT (S, T, Y), oxidation (M).

Reporter ion abundances were corrected for interference by co-isolation ${ }^{5}$ and normalized at protein level. Briefly, the sum of reporter ion S/N values for each PSM was scaled to one. Isolation interference for each channel was assumed to be reflected by the median of corresponding scaled reporter $\mathrm{S} / \mathrm{N}$ values. The $\mathrm{S} / \mathrm{N}$ for each channel were multiplied by (1 - signal interference) to calculate the corresponding interference of each TMT-channel for each PSM. The result was subtracted from S/N values of corresponding TMT-channel in each PSM. Due to this recalculation of $\mathrm{S} / \mathrm{N}$ values, negative values occurred in a frequency below $0.52 \%$ (doxorubicin data set) and these were replaced by the minimum positive value to permit ratio calculation. A moderate quality filter was applied by using only spectra with isolation interference $<0.5$. All LC-MS data have been deposited to the ProteomeXchange Consortium (J.A. Vizcaíno) ${ }^{6}$ via the PRIDE partner repository with the dataset identifier PXD024758. 


\section{Supporting figures}
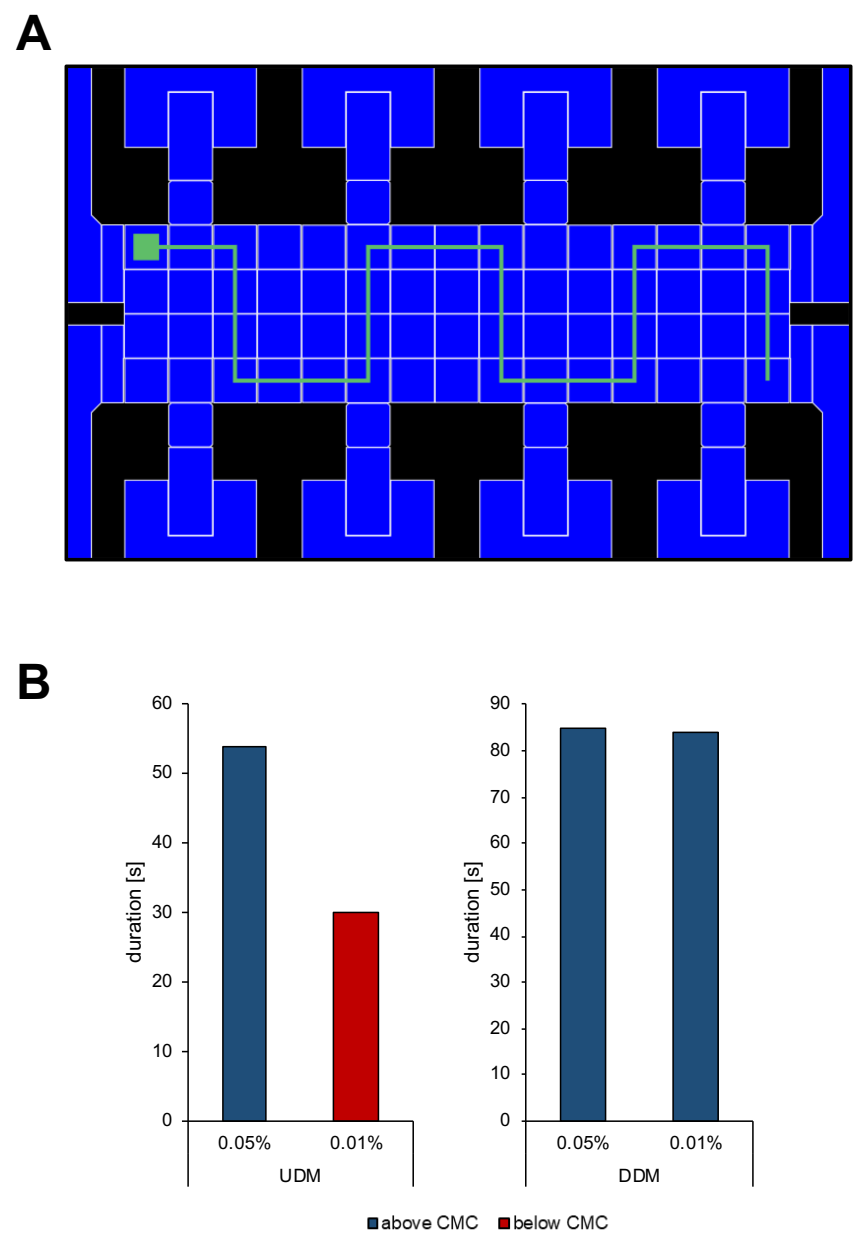

Figure S1: (A) Automatic route pattern programed in the MicroDrop software for tracking of movement duration. Detergent droplets were loaded into the reservoir on the lower right side and were moved onto the starting electrode. For a movement experiment, droplets were moved across the programmed route, with variable step length controlled by the volume threshold parameter set to 1.0. (B) Comparison of movement duration of UDM and DDM detergents at varying concentrations. Bars indicate the duration from experiment start until the droplet reached the destination electrode. At $0.01 \%$ (wt/vol), UDM concentration is below the CMC, but DDM concentration above the CMC. 

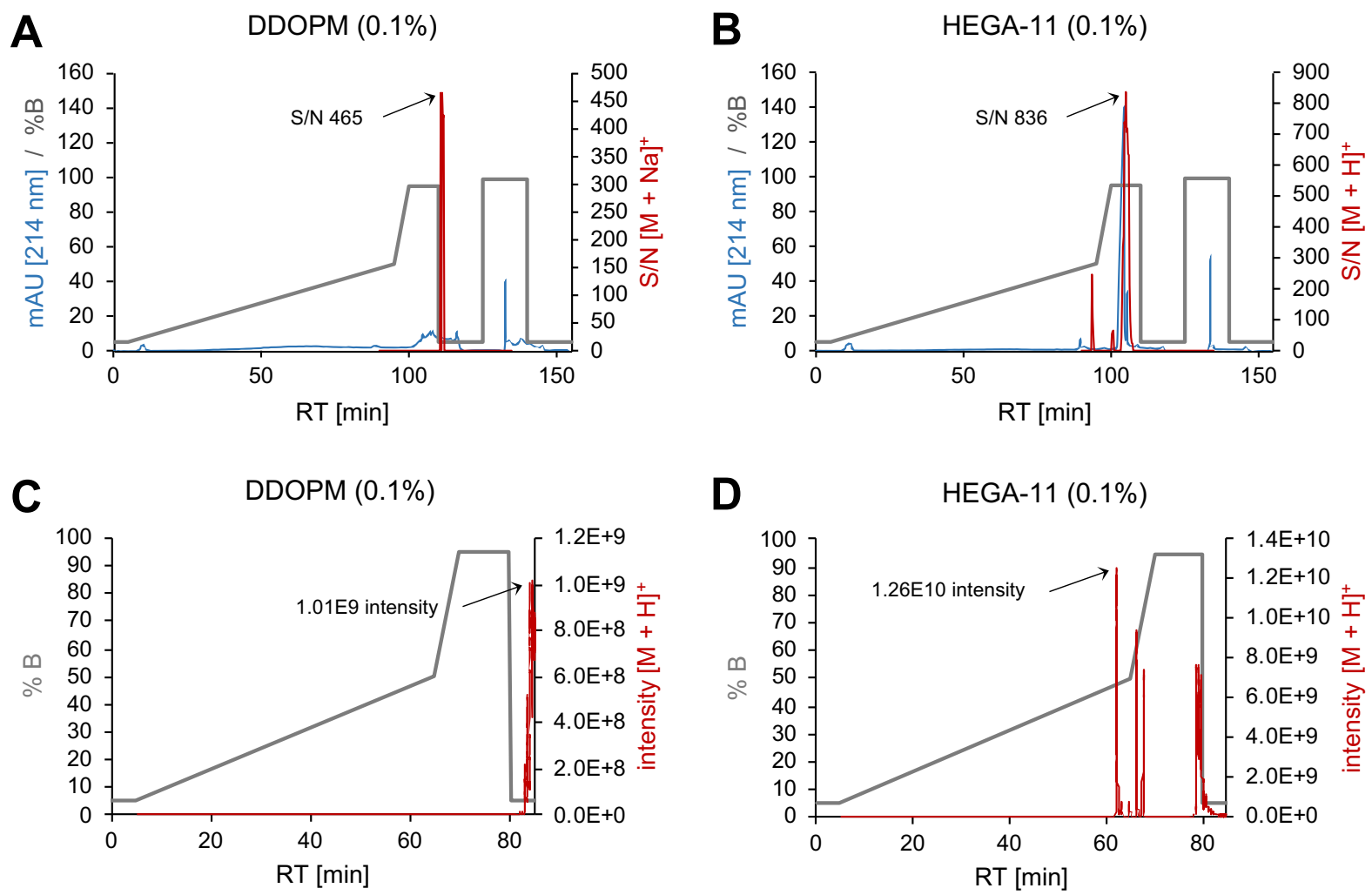

Figure S2: Retention of the detergents in RP-LC. UV-traces $(214 \mathrm{~nm})$ and extracted ion chromatograms (XICs) of LC-MALDI MS of samples containing (A) DDOPM, or (B) HEGA-11, and LC ESI-MS XICs of the protonated molecules of (C) DDOPM or (D) HEGA-11. Grey lines indicate percentage of acetonitrile containing eluent " $\mathrm{B}$ " during the gradient. 

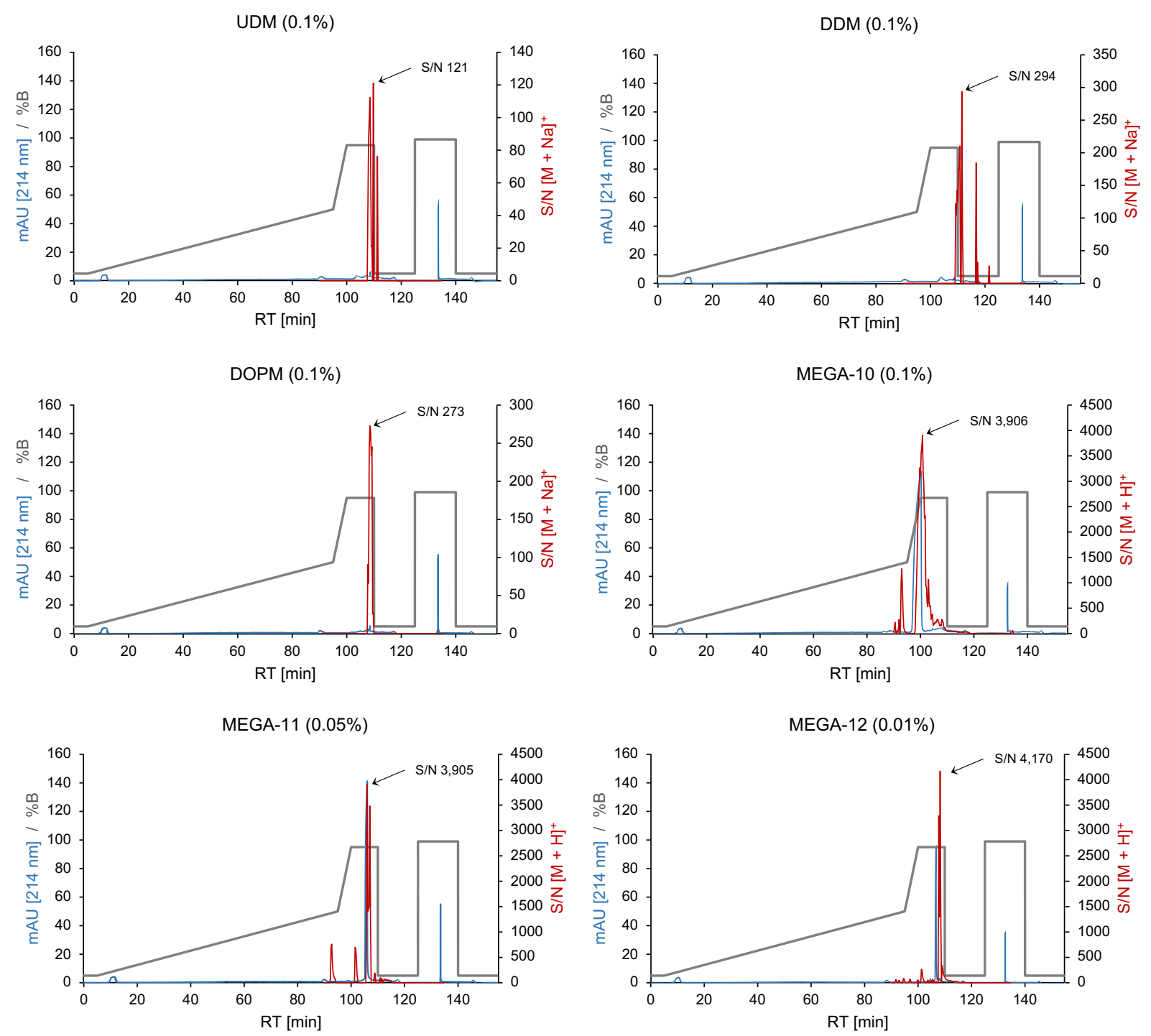

Figure S3: Retention of detergent candidates in $\mathrm{C}_{18}$ RP-LC analyzed by LC-MALDI MS. Shown are the UV-traces $(214 \mathrm{~nm})$ and the LC-MALDI MS extracted ion chromatograms (XICs). Grey lines indicate percentage of acetonitrile containing eluent " $\mathrm{B}$ " during the gradient. Matrix was CHCA; positive ion mode. 
A

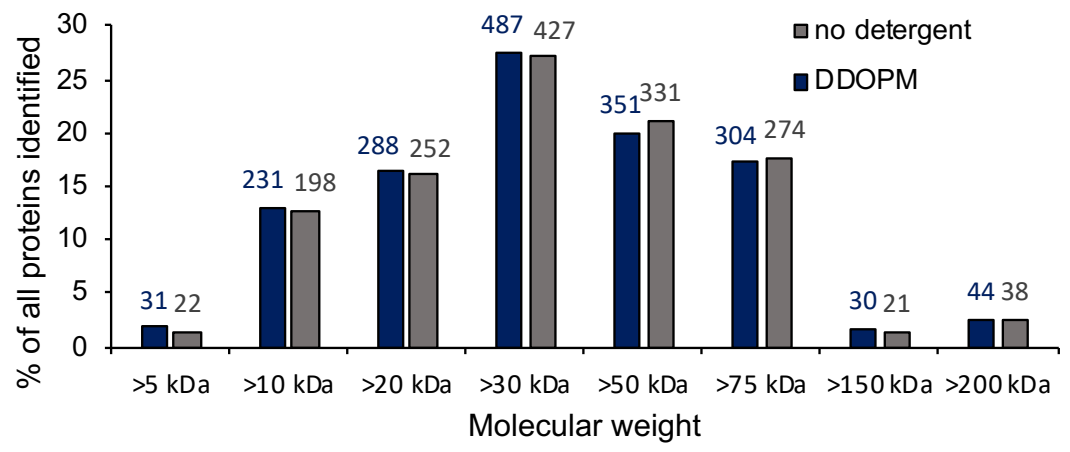

C

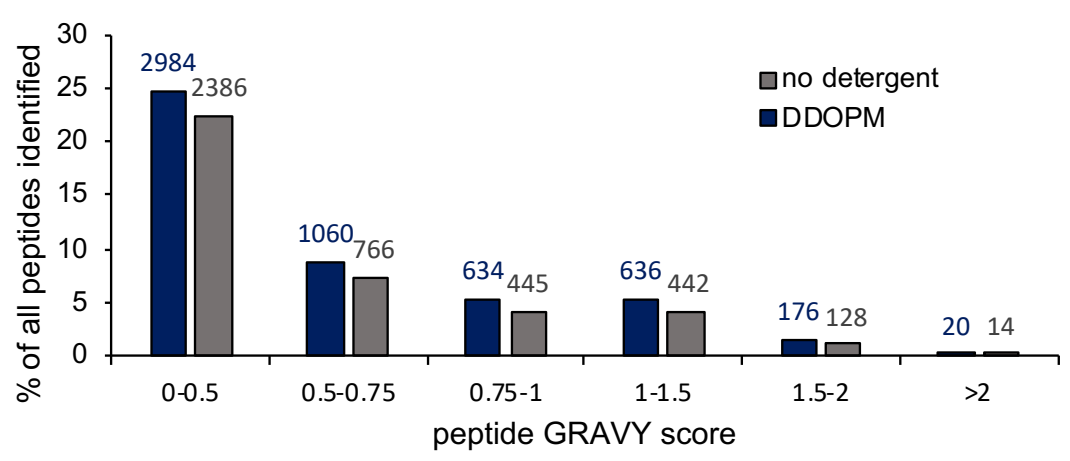

B

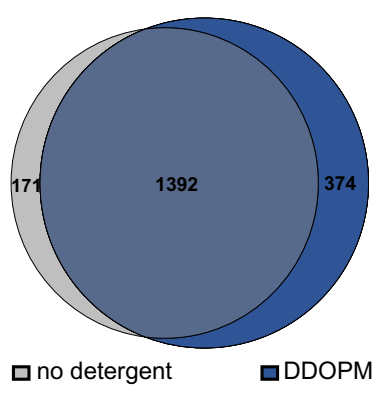

Figure S4: (A) Molecular weight (B) Uniquely identified proteins and overlap of identified proteins between DDOPM and control samples. (C) Comparison of the GRAVY score distribution of peptides with a positive score from DDOPM-containing and detergent-free digests. $y$-axis denotes percentage of all peptides identified. Data show combined identifications of three technical replicates; data labels indicate absolute counts. 
A

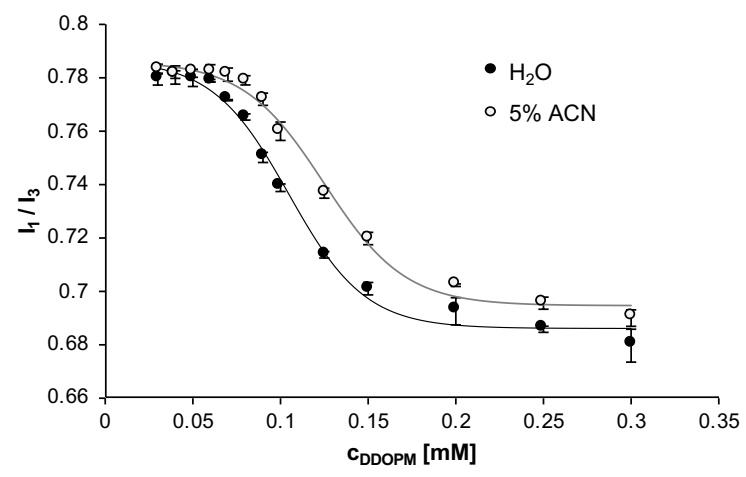

C

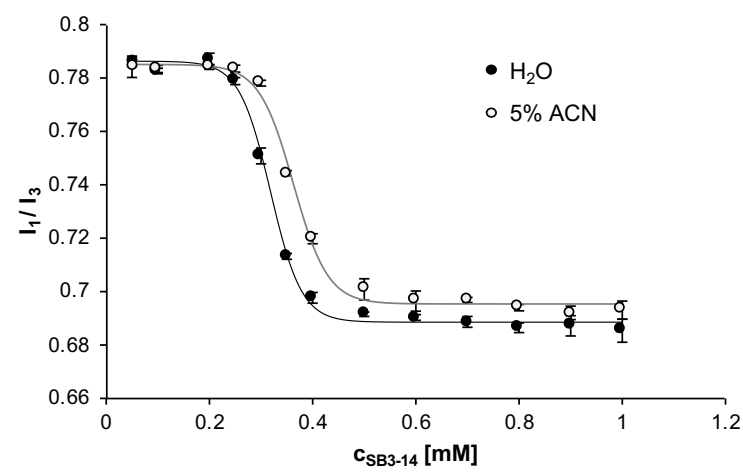

E

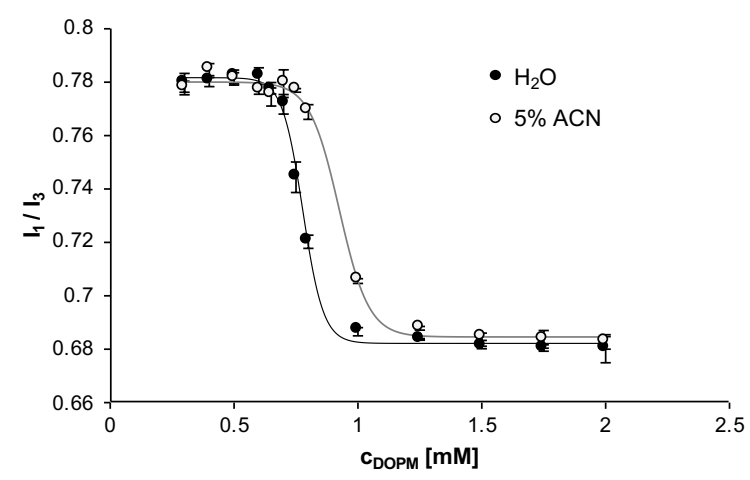

B

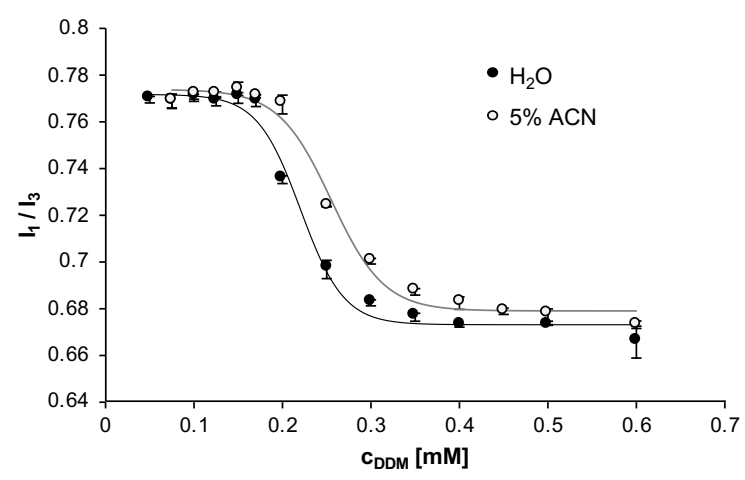

D

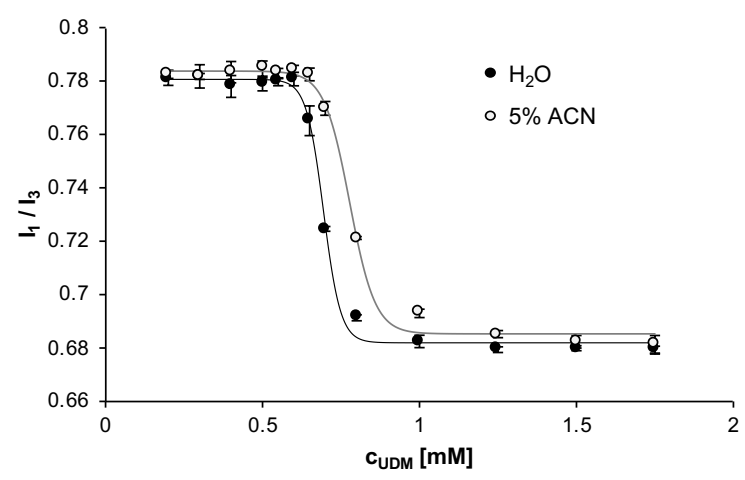

Figure S5: Combined plots of pyrene 1:3 ratios of detergents dissolved in $\mathrm{H}_{2} \mathrm{O}$ or $5 \%$ acetonitrile. (A) DDOPM, (B) DDM, (C) SB3-14, (D) UDM, and (D) DOPM. Concentration series were analyzed as triplicates; error bars are standard deviations. 

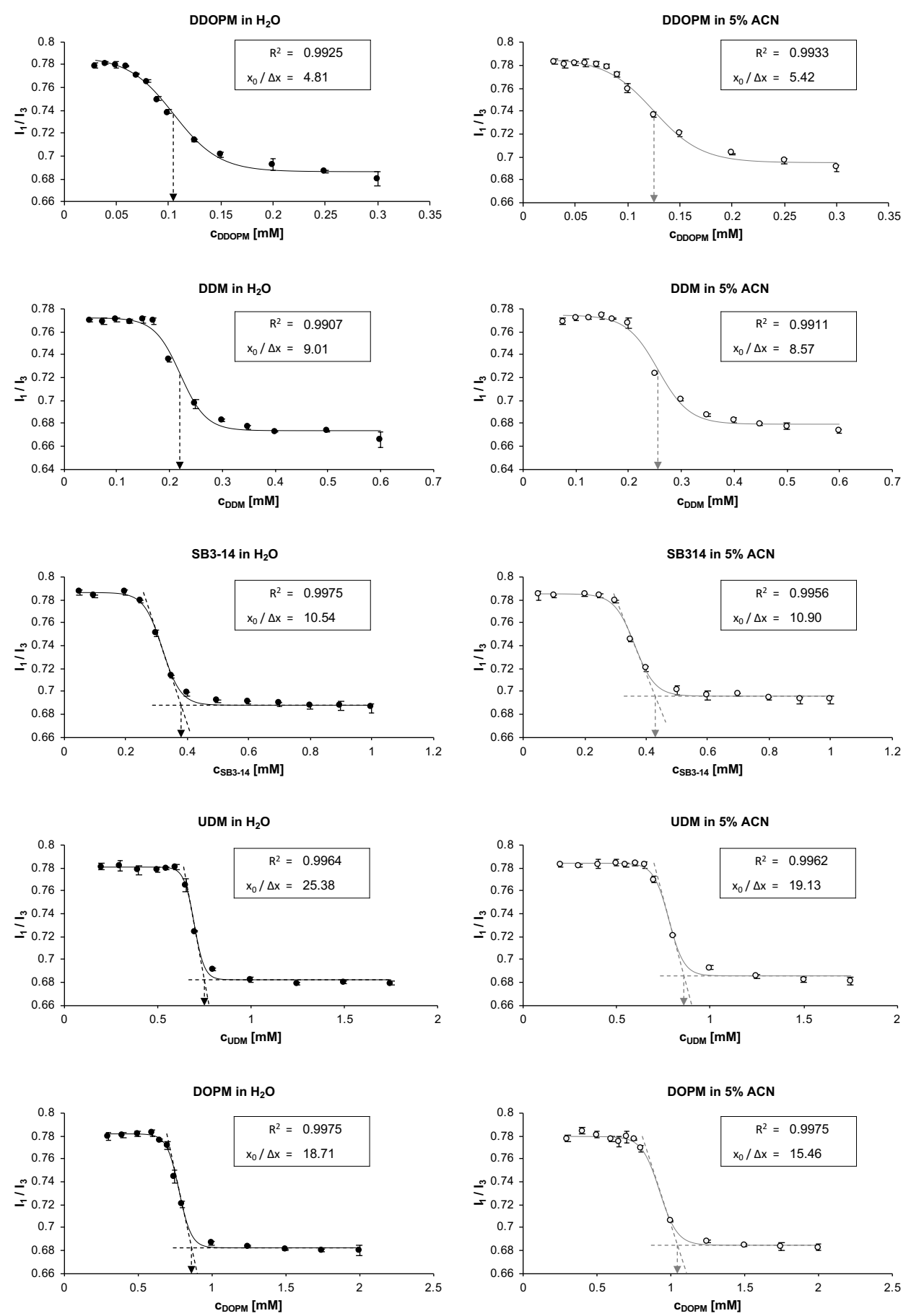

Figure S6: Single plots of pyrene 1:3 ratios of detergents dissolved in $\mathrm{H}_{2} \mathrm{O}$ or $5 \%$ acetonitrile. Concentration series were analyzed as triplicates; error bars are standard deviation. CMCs were determined at the inflection point $x_{0}$ (for detergents with $x_{0} / \Delta x<10$ ), or at the intersection point of $y_{2}$ and the $y_{3}$ tangent to the sigmoid center, being $x_{0}+2 \Delta x$, (for detergents with $x_{0} / \Delta x>$ 10 ). Concentration series were analyzed as triplicates; error bars are standard deviation. 


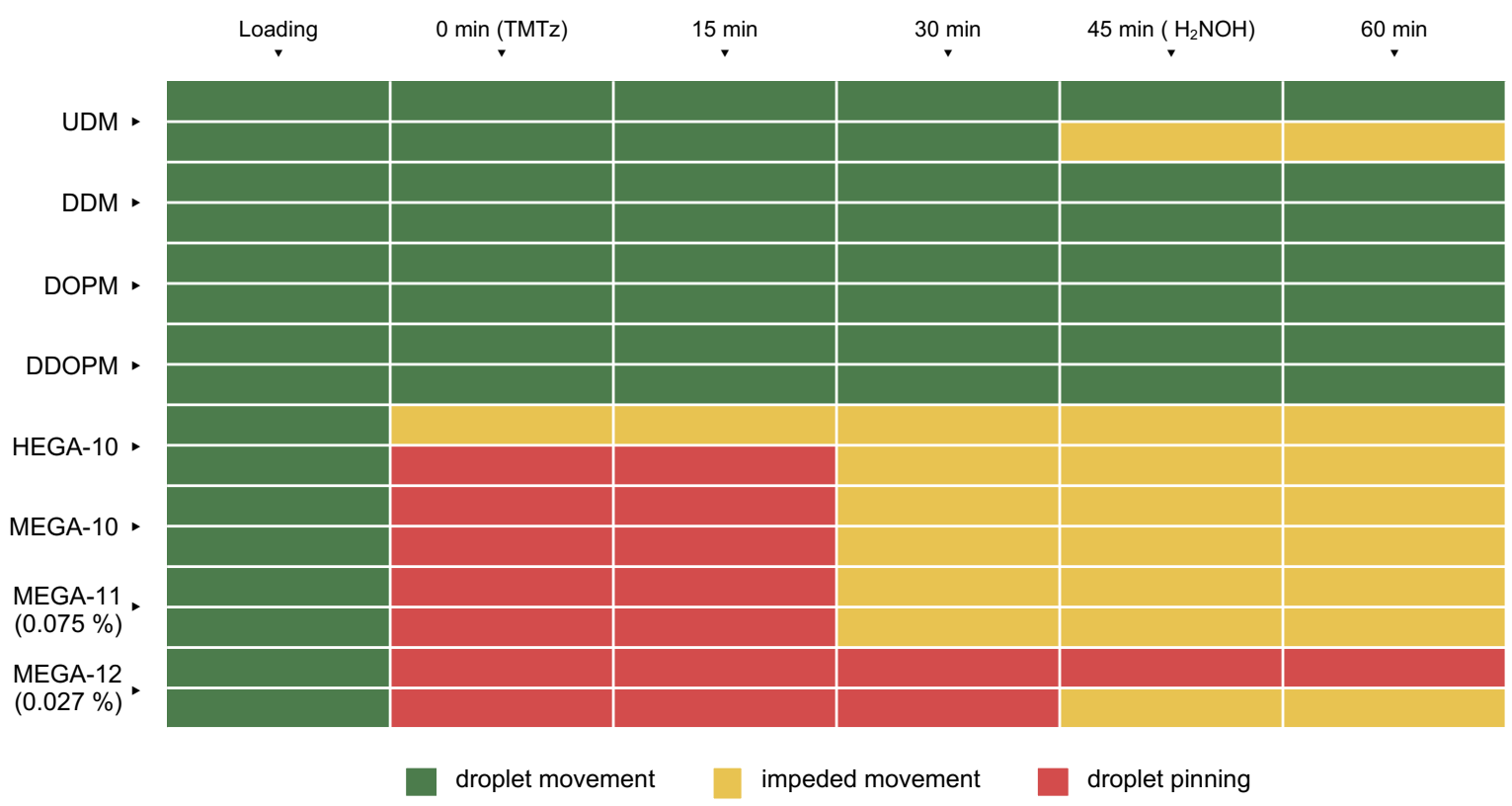

Figure S7: Heatmap indicating droplet movement on DMF (unaffected, impeded movement (incomplete or very slow), or droplet pinning) during the incubation of tryptic digest samples containing detergents with TMTzero (TMTz) reagent dissolved in acetonitrile, and after quenching with hydroxylamine $\left(\mathrm{H}_{2} \mathrm{NOH}\right)$. Duplicate samples were labeled on two individual chip devices. Incubation was carried out under ambient conditions. If not otherwise indicated, detergent concentrations were $0.1 \%$ (wt/vol). 


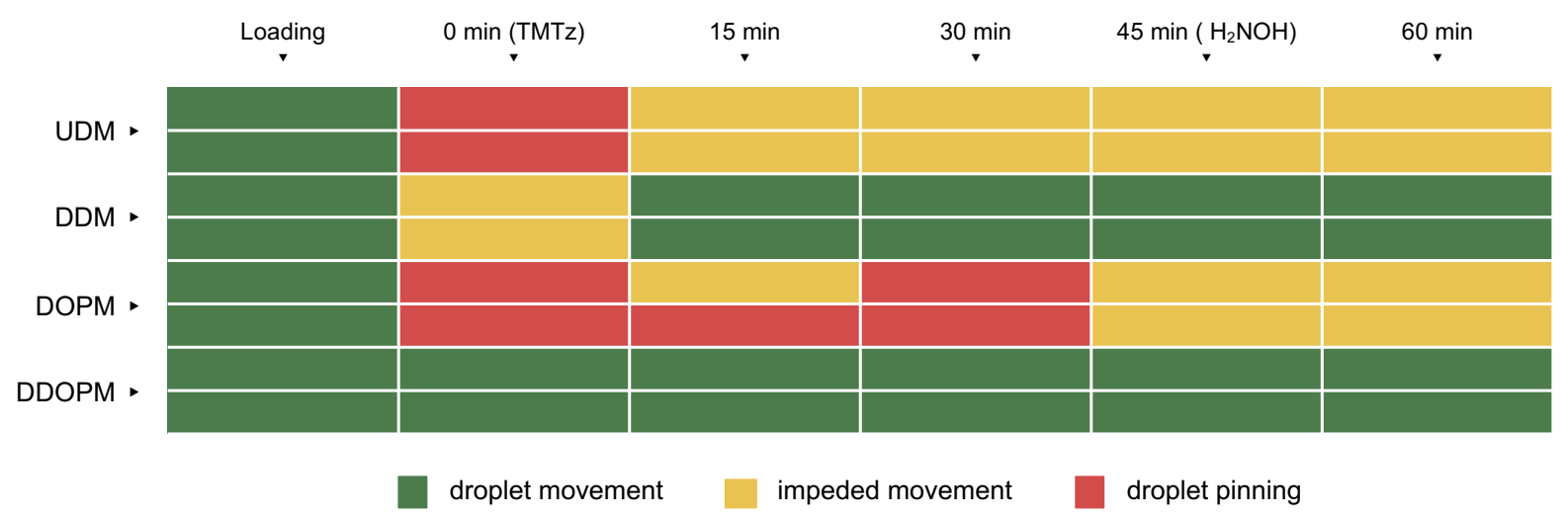

Figure S8: Heatmap indicating unaffected droplet movement, impeded movement (incomplete or very slow), or droplet pinning, during the incubation of tryptic digest samples containing maltoside detergent with TMTzero (TMTz) reagent dissolved in acetonitrile, and after quenching with hydroxylamine $\left(\mathrm{H}_{2} \mathrm{NOH}\right)$. Data shows duplicate samples. Incubation was carried out in an airtight polypropylene container partially filled with $70 \%$ acetonitrile, from where the chip device was only removed for movement tests. Detergent concentrations were $0.1 \%$ (wt $/ \mathrm{vol})$. 

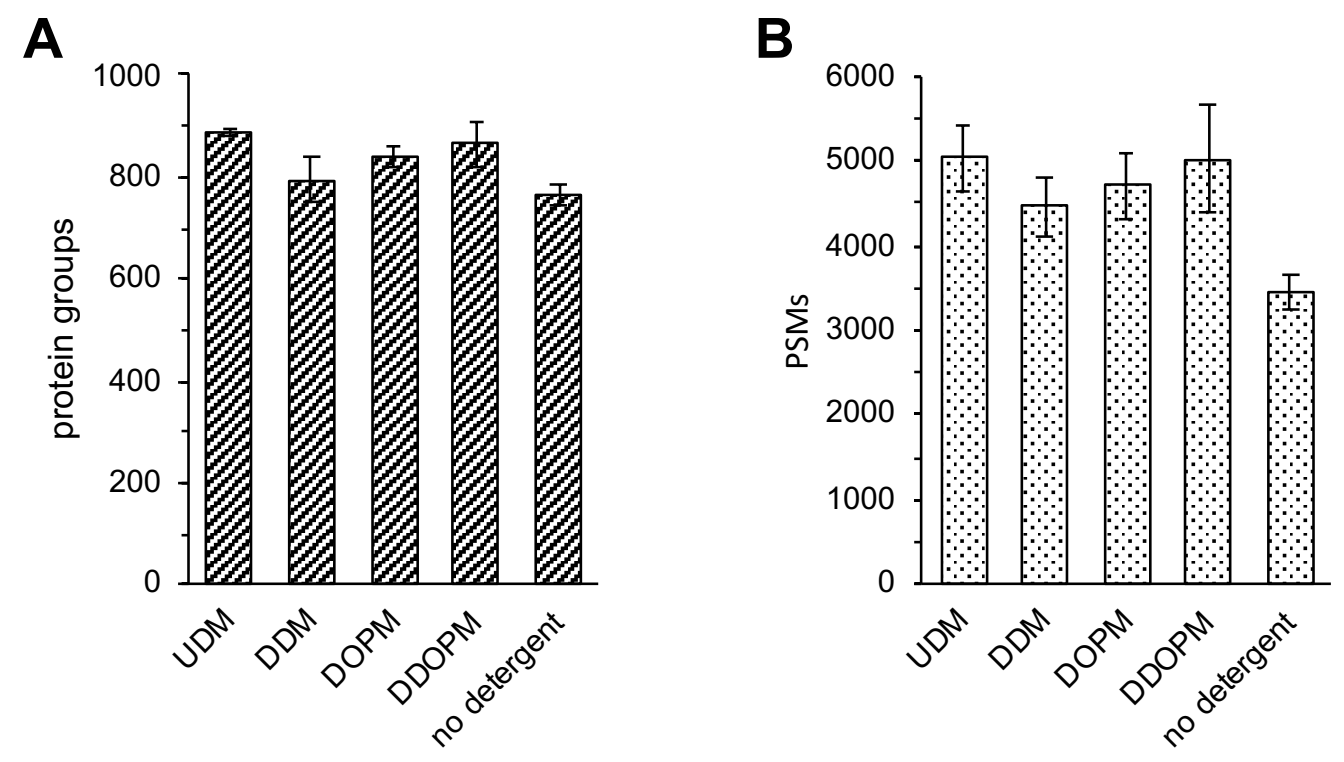

Figure S9: LC-MS analysis of peptide samples labeled with TMTzero on a DMF-chip in the presence of different maltoside detergents. Control samples were detergent-free and prepared in tubes. (A) Fully labeled protein groups identified, and (B) PSMs assigned $(n=2)$. Bars represent technical duplicates labeled on-chip; error bars are standard deviations. 
A

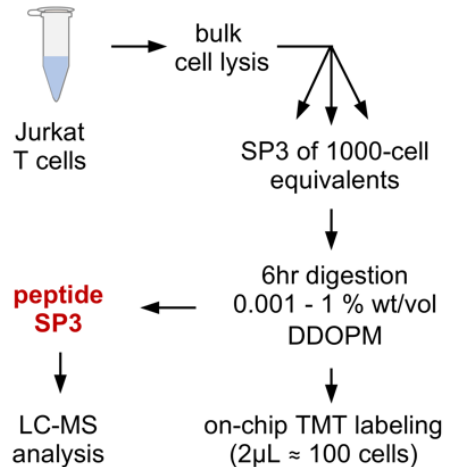

B

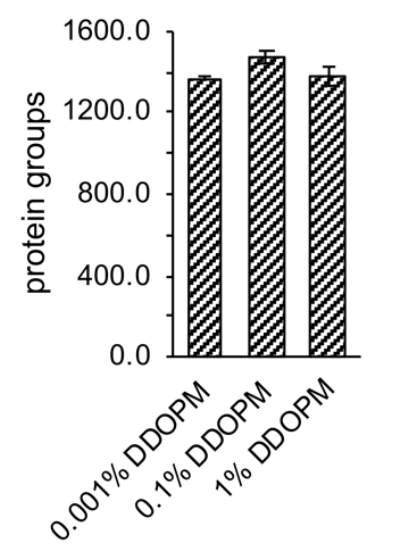

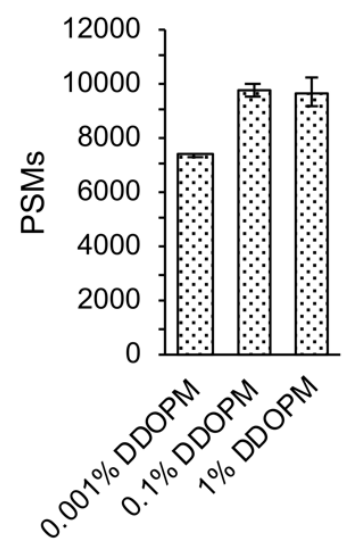

C

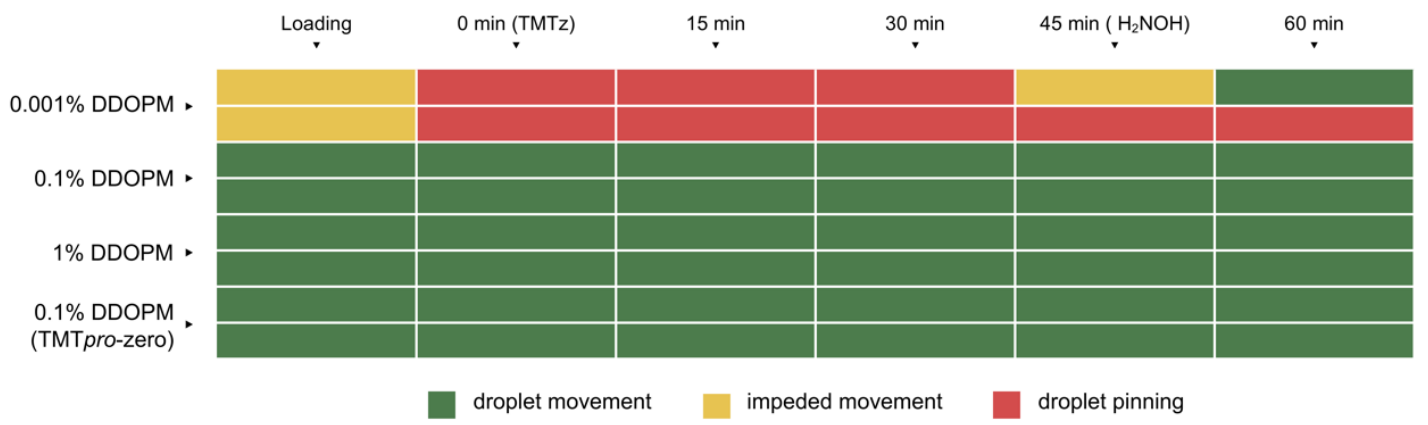

Figure S10: Impact of DDOPM detergent concentrations on the SP3-assisted digestion of Jurkat $\mathrm{T}$ cell lysate, and on-chip droplet movement during TMT labeling. Low (below CMC, 0.001\%), normal (above CMC, LC-MS compatible, 0.1\%), and high (above CMC, not LC-MS compatible, $1 \%$ ) concentrations were tested. (A) Workflow for sample preparation using varying detergent concentrations. To partially remove high detergent amounts (i.e., 1\% DDOPM) from $5 \mu \mathrm{L}$ of digest samples, a one-step SP3 clean-up was performed by addition of SP3-beads (125 $\mu \mathrm{g}$ pellet) and acetonitrile (final concentration of $95 \% \mathrm{ACN}$ ) ${ }^{7,8}$ Peptide elution was performed with $5 \mu \mathrm{L}$ of $2 \%$ dimethyl sulfoxide in $\mathrm{H}_{2} \mathrm{O}$. (B) Protein groups and PSMs identified from injections of 100-cell equivalents after peptide SP3 clean-up of all samples. Bars represent technical triplicates; error bars are standard deviations. (C) Heatmap indicating droplet movement on DMF (unaffected, impeded movement (incomplete or very slow), or droplet pinning) during the open incubation of DDOPM digest samples with TMTzero (TMTz) as well as TMTpro-zero reagent dissolved in acetonitrile, and after quenching with hydroxylamine $\left(\mathrm{H}_{2} \mathrm{NOH}\right)$. 
A

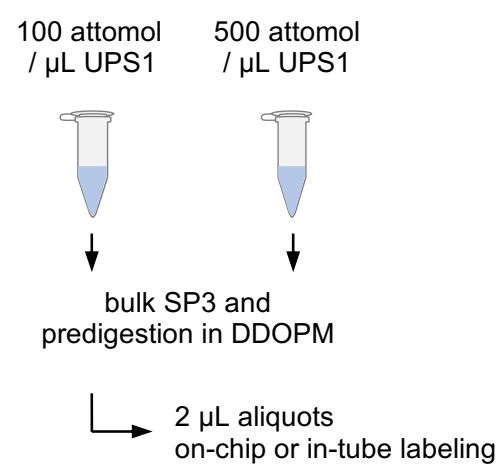

B

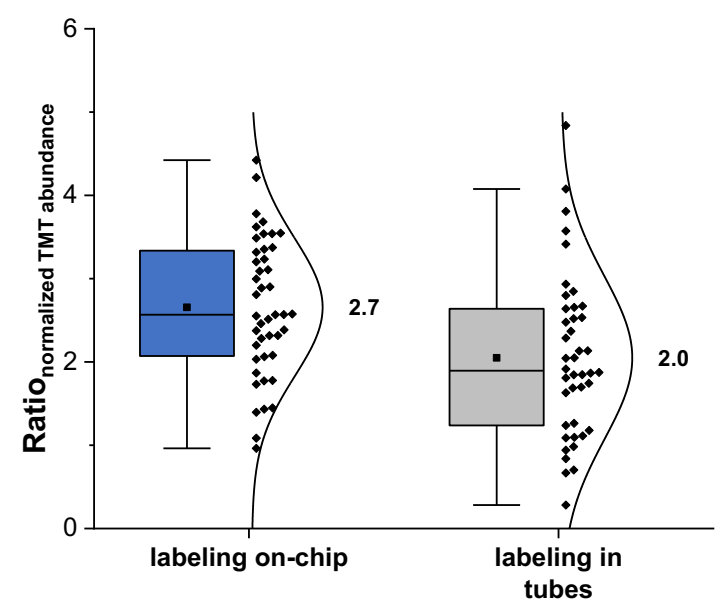

Figure S11: TMT 6-plex analysis of UPS1 proteins predigested without background proteome. (A) Workflow for background-free preparation of dilute bulk SP3 digests for on-chip or in-tube TMT 6-plex labeling. Digest buffer contained DDOPM detergent. Input per channel was 100 or 500 attomoles of UPS1 (3 replicates each). (B) Box plots showing distribution of all quantified UPS1 protein abundance ratios, with mean ratios displayed. As no background proteome was introduced to the samples, a normalization was not performed. 


\section{Supporting tables}

Table S1: Retention times of detergent candidates determined by extracted ion chromatograms of LC-MALDI MS traces, and of glucamides detected by UV absorbance at $214 \mathrm{~nm}$. Detergent CMCs as derived from the literature or manufacturer information are indicated.

\begin{tabular}{|c|c|c|c|c|}
\hline Detergent & Concentration [\% wt/vol] & CMC [\% wt/vol] & RT $_{\text {UV }}$ [min] & RT $_{\text {MALDI }}$ [min] \\
\hline MEGA-10 & 0.1 & $0.23^{\mathrm{a}}$ & 100.21 & 100.75 \\
\hline HEGA-11 & 0.1 & $0.055^{\mathrm{c}}$ & 104.43 & 105.00 \\
\hline MEGA-11 & 0.05 & $0.057^{\mathrm{b}}$ & 106.02 & 106.00 \\
\hline MEGA-12 & 0.01 & $0.013^{\mathrm{b}}$ & 106.71 & 108.25 \\
\hline DOPM & 0.1 & $0.036^{\mathrm{c}}$ & - & 108.50 \\
\hline UDM & 0.1 & $0.029^{\mathrm{c}}$ & - & 109.75 \\
\hline DDOPM & 0.1 & $0.0032^{\mathrm{d}}$ & - & 110.75 \\
\hline DDM & 0.1 & $0.0087^{\mathrm{d}}$ & - & 111.50 \\
\hline
\end{tabular}

\footnotetext{
${ }^{\mathrm{a}}$ reference $^{9}$

${ }^{\mathrm{b}}$ reference ${ }^{10}$

${ }^{\mathrm{c}}$ manufacturer information

d manufacturer estimation
} 
Table S2: Reference critical micelle concentrations (CMCs) and CMCs determined by pyrene 1:3 ratio method in $\mathrm{H}_{2} \mathrm{O}$ or $5 \%$ acetonitrile $\left(\mathrm{ACN}\right.$ ). CMCs were determined at the inflection point $x_{0}$ (for detergents with $x_{0} / \Delta x<10$ ), or at the intersection point of $y_{2}$ and the $y_{3}$ tangent to the sigmoid center, being $x_{0}+2 \Delta x$ (for detergents with $x_{0} / \Delta x>10$ ). Increase of CMC by $5 \% \mathrm{ACN}$ is listed for both methods, with the value underlined, which was calculated based on the $x_{0} / \Delta x$ criterion. The $x_{0} / \Delta x$ ratios for each sigmoid are shown in Figure S6.

\begin{tabular}{|c|c|c|c|c|c|}
\hline \multirow[b]{2}{*}{ Detergent } & \multirow[b]{2}{*}{$\mathrm{CMC}_{\mathrm{H}_{2} \mathrm{O}}[\mathrm{mM}]$} & \multirow[b]{2}{*}{$\mathrm{CMC}_{5 \%} \%$ ACN $[\mathrm{mM}]$} & \multirow[b]{2}{*}{ Literature CMC [mM] } & \multicolumn{2}{|c|}{ Increase of CMC by $5 \% \mathrm{ACN}[\mathrm{mM}]$} \\
\hline & & & & $\mathrm{CMC}=x_{0}$ & $\mathrm{CMC}=x_{0}+2 \Delta x$ \\
\hline DDOPM & 0.105 & 0.125 & $0.060^{\mathrm{a}}$ & $\underline{0.020}$ & 0.023 \\
\hline DDM & 0.220 & 0.255 & $0.152^{b}$ & $\underline{0.035}$ & 0.045 \\
\hline SB314 & 0.379 & 0.429 & $0.250^{\mathrm{c}}$ & 0.045 & $\underline{0.051}$ \\
\hline UDM & 0.749 & 0.859 & $0.580^{\mathrm{b}}$ & 0.083 & $\underline{0.110}$ \\
\hline DOPM & 0.861 & 1.044 & $0.660^{\mathrm{a}}$ & 0.147 & $\underline{0.184}$ \\
\hline
\end{tabular}

\footnotetext{
${ }^{\text {a }}$ manufacturer estimation

${ }^{\mathrm{b}}$ manufacturer information

${ }^{\mathrm{c}}$ different values for SB314 were reported; manufacturer information is $0.1-0.4 \mathrm{mM}$
} 
Table S3: Hydrophilic-lipophilic balance (HLB) values and solubilities of the investigated maltoside and glucamide detergents. HLB values were calculated using the method described by Griffin or Davies. ${ }^{11,12}$ To assess solubility, glucamides were initially dissolved by heating to $45-50^{\circ} \mathrm{C}$ in a water bath until a clear solution was obtained.

\begin{tabular}{|c|c|c|c|}
\hline Detergent & HLB (Griffin's method) & HLB (Davies' method) & Solubility in H2O (\% wt/vol) \\
\hline UDM & 13.75 & 14.58 & $\geq 20^{\mathrm{a}}$ \\
\hline DDM & 13.37 & 14.10 & $\geq 1^{\mathrm{b}}$ \\
\hline DOPM & 14.77 & 14.93 & $\geq 1^{\mathrm{b}}$ \\
\hline DDOPM & 14.05 & 11.78 & $\geq 0.5^{\mathrm{a}}$ \\
\hline HEGA-11 & 12.82 & 10.83 & $0.2^{\mathrm{c}}$ \\
\hline MEGA-10 & 12.72 & 10.35 & $0.1^{\mathrm{c}}$ \\
\hline MEGA-11 & 12.23 & 9.88 & $0.02^{\mathrm{c}}$ \\
\hline
\end{tabular}

${ }^{a}$ manufacturer information

${ }^{b}$ highest concentration tested in this study

${ }^{c}$ highest concentration without precipitation after $24 \mathrm{~h}$ incubation at $4^{\circ} \mathrm{C}$ 
Table S4: Number of quantified peptides and quantified PSMs of UPS1 proteins. Proteins of the UPS1 mixture not identified are indicated by n.i.; for identified but not quantified UPS1 proteins, the number of identified peptides and PSMs is listed in parentheses.

\begin{tabular}{|c|c|c|c|c|c|c|c|}
\hline \multirow[b]{3}{*}{ Accession } & \multirow[b]{3}{*}{ Description } & \multirow{2}{*}{\multicolumn{2}{|c|}{$\begin{array}{c}\begin{array}{c}\text { UPS1 with } \\
\text { background }\end{array} \\
\text { DMF-SP3-TMT }\end{array}$}} & \multicolumn{4}{|c|}{ UPS1 without background } \\
\hline & & & & \multicolumn{2}{|c|}{$\begin{array}{l}\text { Predigest and } \\
\text { tube-TMT }\end{array}$} & \multicolumn{2}{|c|}{$\begin{array}{l}\text { Predigest and } \\
\text { DMF-TMT }\end{array}$} \\
\hline & & 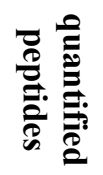 & 尝 & : & 㿣 & 氧 & 疍 \\
\hline P00709 & Alpha-lactalbumin & 2 & 2 & 1 & 1 & 2 & 3 \\
\hline P08758 & Annexin A 5 & 17 & 18 & 7 & 7 & 6 & 7 \\
\hline P01008 & Antithrombin-III & 15 & 17 & 6 & 7 & 9 & 10 \\
\hline P61769 & Beta-2-microglobulin & 2 & 2 & 1 & 1 & 1 & 1 \\
\hline P55957 & BH3 Interacting domain death agonist & 4 & 4 & 1 & 1 & 1 & 1 \\
\hline $\mathrm{P} 02741$ & C-reactive protein & 4 & 5 & 3 & 4 & 2 & 3 \\
\hline P00915 & Carbonic anhydrase 1 & 8 & 10 & 7 & 8 & 12 & 18 \\
\hline P00918 & Carbonic anhydrase 2 & 5 & 6 & 9 & 11 & 3 & 5 \\
\hline P04040 & Catalase & 15 & 19 & 12 & 16 & 12 & 18 \\
\hline P01031 & Complement C5 & 3 & 4 & 5 & 5 & 3 & 3 \\
\hline P06732 & Creatine kinase M-type & 10 & 10 & 14 & 15 & 11 & 11 \\
\hline P00167 & Cytochrome $b_{5}$ & 1 & 1 & 1 & 1 & n.i. & n.i. \\
\hline P99999 & Cytochrome c & 6 & 7 & 6 & 8 & 6 & 7 \\
\hline $\mathrm{P} 01133$ & Epidermal Growth Factor & n.i. & $n . i$. & n.i. & n.i. & n.i. & $n . i$. \\
\hline P05413 & Fatty acid-binding protein & 8 & 9 & (4) & (4) & 1 & 1 \\
\hline O76070 & Gamma-synuclein & 9 & 11 & 6 & 7 & 6 & 7 \\
\hline P06396 & Gelsolin & 25 & 28 & 19 & 24 & 19 & 29 \\
\hline $\mathrm{P} 08263$ & Glutathione S-transferase A1 & (6) & (7) & 1 & 1 & (8) & (10) \\
\hline P09211 & Glutathione S-transferase P & 9 & 13 & 2 & 2 & 2 & 2 \\
\hline $\mathrm{P} 01112$ & GTPase Hras & 2 & 2 & (4) & (4) & (3) & (4) \\
\hline
\end{tabular}




\begin{tabular}{|c|c|c|c|c|c|c|c|}
\hline P69905 & Hemoglobin alpha chain & 1 & 1 & 2 & 2 & 1 & 1 \\
\hline P68871 & Hemoglobin beta chain & 1 & 1 & 2 & 2 & $n . i$. & n.i. \\
\hline P12081 & Histidyl-tRNA synthetase & 18 & 22 & 21 & 25 & 13 & 14 \\
\hline $\mathrm{P} 01344$ & Insulin-like growth factor II & 3 & 3 & 2 & 3 & 3 & 3 \\
\hline P01579 & Interferon gamma (IFN-gamma) & 2 & 3 & 4 & 6 & 11 & 13 \\
\hline P10145 & Interleukin- 8 & 1 & 1 & 2 & 2 & (2) & (2) \\
\hline P02788 & Lactotransferrin & 30 & 39 & 27 & 36 & 27 & 34 \\
\hline P41159 & Leptin & 2 & 2 & 2 & 2 & 3 & 3 \\
\hline P61626 & Lysozyme C & 1 & 1 & 3 & 3 & 6 & 7 \\
\hline P10636 & Microtubule-associated protein tau & 13 & 19 & 11 & 13 & 12 & 17 \\
\hline $\mathrm{P} 02144$ & Myoglobin $\mathrm{C}$ & 5 & 6 & 5 & 8 & 8 & 8 \\
\hline P15559 & NAD(P)H dehydrogenase 1 & 8 & 10 & 10 & 11 & 9 & 10 \\
\hline Q15843 & Neddylin & 1 & 1 & (1) & (1) & 3 & 3 \\
\hline P62937 & Peptidyl-prolyl cis-trans isomerase A & 8 & 15 & 7 & 9 & 7 & 7 \\
\hline Q06830 & Peroxiredoxin 1 & 13 & 18 & 7 & 8 & 4 & 4 \\
\hline P01127 & Platelet-derived growth factor B chain & 3 & 4 & 2 & 2 & 2 & 2 \\
\hline $\mathrm{P} 02753$ & Retinol-binding protein & 9 & 10 & 4 & 4 & 7 & 9 \\
\hline P16083 & $\begin{array}{l}\text { Ribosyldihydronicotinamide } \\
\text { dehydrogenase }\end{array}$ & 4 & 4 & 4 & 4 & 2 & 2 \\
\hline P02787 & Serotransferrin & 32 & 39 & 26 & 31 & 31 & 38 \\
\hline P02768 & Serum Albumin & 30 & 35 & 20 & 28 & 20 & 28 \\
\hline P63165 & Small ubiquitin-related modifier 1 & 11 & 15 & 11 & 14 & 12 & 14 \\
\hline P00441 & Superoxide dismutase & 10 & 10 & 2 & 2 & 2 & 2 \\
\hline P10599 & Thioredoxin & 7 & 7 & 5 & 6 & 3 & 3 \\
\hline P01375 & Tumor necrosis factor & 6 & 8 & 4 & 5 & 7 & 7 \\
\hline P62988 & Ubiquitin & 3 & 5 & 1 & 1 & 1 & 1 \\
\hline $\mathrm{O} 00762$ & Ubiquitin-conjugating enzyme E2 C & 5 & 6 & 3 & 4 & 7 & 8 \\
\hline P51965 & Ubiquitin-conjugating enzyme E2 E1 & 3 & 4 & 2 & 2 & 3 & 4 \\
\hline P63279 & Ubiquitin-conjugating enzyme E2 I & 2 & 3 & 1 & 1 & 2 & 2 \\
\hline
\end{tabular}


Table S5: Differentially abundant proteins quantified from Jurkat T cells after treatment with doxorubicin. Considered were proteins with $>1.4-/<0.71$-fold change and $p<0.05$, accepting single unique peptides for quantification. Ratios derived from quantification using single unique peptides are indicated ${ }^{(*)}$.

\begin{tabular}{|c|c|c|c|}
\hline Accession & Description & Ratio doxorubicin / untreated & $p$-value \\
\hline P35269 & General transcription factor IIF subunit 1 & $4.53(*)$ & 0.003 \\
\hline P12259 & Coagulation factor $\mathrm{V}$ & 3.05 & 0.002 \\
\hline Q9Y2V2 & Calcium-regulated heat-stable protein 1 & 2.76 & 0.031 \\
\hline Q9H1E3 & Nuclear ubiquitous casein and cyclin-dependent kinase substrate 1 & $2.63^{(*)}$ & 0.002 \\
\hline Q13427 & Peptidyl-prolyl cis-trans isomerase $\mathrm{G}$ & 2.32 & 0.001 \\
\hline P33316 & Deoxyuridine 5'-triphosphate nucleotidohydrolase, mitochondrial & 1.82 & 0.032 \\
\hline P12236 & ADP/ATP translocase 3 & 1.60 & 0.008 \\
\hline P30101 & Protein disulfide-isomerase & 1.57 & 0.015 \\
\hline P48735 & Isocitrate dehydrogenase [NADP], mitochondrial & 1.47 & 0.007 \\
\hline Q14157 & Ubiquitin-associated protein 2-like & 0.71 & 0.024 \\
\hline P31943 & Heterogeneous nuclear ribonucleoprotein $\mathrm{H}$ & 0.70 & 0.001 \\
\hline P84243 & Histone H3.3 & 0.70 & 0.007 \\
\hline Q9BZE4 & Nucleolar GTP-binding protein & 0.68 & 0.024 \\
\hline O75821 & Eukaryotic translation initiation factor 3 subunit $G$ & 0.68 & 0.004 \\
\hline Q9Y3Y2 & Chromatin target of PRMT1 protein & $0.68^{(*)}$ & 0.032 \\
\hline Q96C01 & Protein FAM136A & $0.68^{(*)}$ & 0.013 \\
\hline Q9H444 & Charged multivesicular body protein $4 \mathrm{~b}$ & 0.67 & 0.017 \\
\hline P05386 & $60 \mathrm{~S}$ acidic ribosomal protein $\mathrm{P} 1$ & $0.67^{(*)}$ & 0.020 \\
\hline Q9GZT3 & SRA stem-loop-interacting RNA-binding protein, mitochondrial & $0.66^{(*)}$ & 0.038 \\
\hline Q9UNZ5 & Leydig cell tumor $10 \mathrm{kDa}$ protein homolog & 0.66 & 0.018 \\
\hline P40222 & Alpha-taxilin & $0.65^{(*)}$ & 0.003 \\
\hline P62987 & Ubiquitin-60S ribosomal protein L40 & $0.65^{(*)}$ & 0.001 \\
\hline Q86V81 & THO complex subunit 4 & 0.64 & 0.046 \\
\hline
\end{tabular}




\begin{tabular}{|c|c|c|c|}
\hline P62847 & 40S ribosomal protein S24 & 0.64 & 0.004 \\
\hline Q9BZL1 & Ubiquitin-like protein 5 & 0.63 & 0.029 \\
\hline P14735 & Insulin-degrading enzyme & 0.62 & 0.033 \\
\hline O76021 & Ribosomal L1 domain-containing protein 1 & 0.61 & 0.023 \\
\hline Q13895 & Bystin & 0.60 & 0.002 \\
\hline Q9Y2S6 & Translation machinery-associated protein 7 & 0.59 & 0.017 \\
\hline Q99439 & Calponin-2 & $0.56^{(*)}$ & 0.001 \\
\hline Q14011 & Cold-inducible RNA-binding protein & $0.55^{(*)}$ & $0.036^{(*)}$ \\
\hline Q9NZ63 & Uncharacterized protein C9orf78 & 0.45 & 0.011 \\
\hline Q9NZZ3 & Charged multivesicular body protein 5 & $0.45^{(*)}$ \\
\hline P41567 & Eukaryotic translation initiation factor 1 & 0.43 \\
\hline Q15397 & Pumilio homolog 3 & 0.39 \\
\hline P52292 & Importin subunit alpha-1 & $0.034^{(*)}$ \\
\hline Q15056 & Eukaryotic translation initiation factor 4H & 0.025 \\
\hline P98179 & RNA-binding protein 3 & 0.31 & 0.0001 \\
\hline P08670 & Vimentin & 0.006 \\
\hline
\end{tabular}




\section{Supporting references}

1 X. Dong, L. Xiong, X. Jiang and Y. Wang, J. Proteome Res., 2010, 9, 5943-5951.

2 K. Kalyanasundaram and J. K. Thomas, Journal of the American Chemical Society, 1977, 99, 2039-2044.

3 J. Aguiar, P. Carpena, J. A. Molina-Bolívar and C. Carnero Ruiz, Journal of Colloid and Interface Science, 2003, 258, 116-122.

4 H. J. Motulsky and R. E. Brown, BMC Bioinformatics, 2006, 7, 123.

5 M. M. Savitski, T. Mathieson, N. Zinn, G. Sweetman, C. Doce, I. Becher, F. Pachl, B. Kuster and M. Bantscheff, J. Proteome Res., 2013, 12, 3586-3598.

6 J. A. Vizcaíno, E. W. Deutsch, R. Wang, A. Csordas, F. Reisinger, D. Ríos, J. A. Dianes, Z. Sun, T. Farrah, N. Bandeira, P.-A. Binz, I. Xenarios, M. Eisenacher, G. Mayer, L. Gatto, A. Campos, R. J. Chalkley, H.-J. Kraus, J. P. Albar, S. Martinez-Bartolomé, R. Apweiler, G. S. Omenn, L. Martens, A. R. Jones and H. Hermjakob, Nature Biotechnology, 2014, 32, 223-226.

7 C. S. Hughes, S. Foehr, D. A. Garfield, E. E. Furlong, L. M. Steinmetz and J. Krijgsveld, Molecular Systems Biology, 2014, 10, 757.

8 M. Sielaff, J. Kuharev, T. Bohn, J. Hahlbrock, T. Bopp, S. Tenzer and U. Distler, J. Proteome Res., 2017, 16, 4060-4072.

9 G. Basu Ray, I. Chakraborty and S. P. Moulik, Journal of Colloid and Interface Science, 2006, 294, 248-254.

10 Y.-P. Zhu, M. J. Rosen, P. K. Vinson and S. W. Morrall, J Surfact Deterg, 1999, 2, 357-362.

11 W. C. Griffin, J. Soc. Cosmet. Chem., 1954, 5, 249-256.

12 J. T. Davies, in Proc. 2nd Int. Congr. Surface Activity. 1: 426. -103-of references, 1957. 